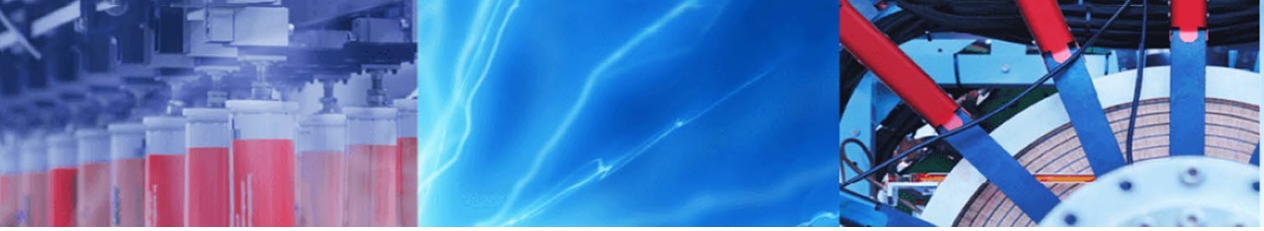

Research Article

\title{
Applying response surface methodology on the results of serial sequencing batch moving bed reactor
}

\author{
Mahdi Ghaderi ${ }^{1}$ Pariya Asadi ${ }^{2}$. Mahtab Kouhirostamkolaei ${ }^{2}$
}

Received: 23 September 2019 / Accepted: 11 December 2019 / Published online: 20 December 2019

(c) Springer Nature Switzerland AG 2019

\begin{abstract}
This study introduces the new biological reactor that called serial sequencing batch moving bed reactor. In this research, this reactor was used for treatment of hospital wastewater. Furthermore, three independent variables (retention time, pollutant loading and media filling percentage) were investigated. For the first time, modeling of COD removal percentage (as the dependent variable) in hospital wastewater treatment was investigated by using of response surface methodology. According to the results, the COD removal efficiency increased from 58 to $91 \%$, when pollutant loading decreased from 0.38 to $0.3 \mathrm{kgCOD} / \mathrm{kgMLSS}$. Also, COD removal efficiency increased from 38 to $86 \%$ when retention time increased from 16.48 to $58.52 \mathrm{~h}$. According to the results, the media filling percentage had the minimum effect on the COD removal efficiency, so that, COD removal efficiency increased from 63 to $78 \%$ with increasing in media filling percentage from 19.77 to $45 \%$. The results revealed that the optimum condition to achieving the highest COD removal efficiency was at the retention time of $46.59 \mathrm{~h}$, pollutant loading of $0.34 \mathrm{kgCOD} / \mathrm{kgMLSS}$ and media filling percentage of $42.24 \%$. According to this research results, this reactor have high efficiency in hospital wastewater treatment.
\end{abstract}

Keywords Media filling percentage $\cdot$ Pollutant loading $\cdot$ Response surface methodology $\cdot$ Retention time $\cdot$ Serial sequencing batch moving bed reactor

\section{Introduction}

As the population growth, the widespread use of industry and medicine have led to a larger volume of sewage containing contaminants [1,2]. The treatment of industrial wastewater were investigated in previous studies $[3,5,10$, $26,29,30,45,46,58]$. The pharmaceutical ingredients do not completely alter in the human body and it flows into the sewage system. These kind of contaminants remain unchanged during wastewater treatment operations. The stability of pharmaceutical ingredients in surface and underground water sources has given rise to numerous diseases. Medicines downgrade the quality of water and leave a toxic effect on microorganisms. Over the last two decades, studies have focused on this materials, its effects and the removal of residual contaminants from the environment [55]. A hospital wastewater contains huge amounts of active pharmaceutical ingredients (APIs), discharge a substantial volume of medicines into urban sewage. Hospitals are the major consumers of antibiotics, which cause spread of antibiotic resistance [36].

Previously, physical, chemical and biological processes have been used for treatment of wastewaters. Numerous studies have been conducted on the hospital wastewater treatment $[4,11,25,27,28,35,51,52]$. Using of nano materials and studying about nanofluids are new research interests in environmental engineering [37-44, 47-49]. Based on the results published by Hocquet et al., it was found that great quantities of antimicrobials discharged in wastewater have been stable [15]. Another research by

Mahdi Ghaderi, m.ghadery.ace@gmail.com | ${ }^{1}$ Mechanical Engineering Division, Torbat-e Jam High Educational Complex, Torbat-e Jam, Iran. ${ }^{2}$ Faculty of Civil Engineering, Babol Noshirvani University of Technology, Babol, Iran. 
Han Tran et al. [14] showed the presence of 10 different antimicrobials in Singaporean wastewater samples. In a study by Walia et al. [56] the spread of $\beta$-lactamase spectrum (BL) and its resistance gene in hospital effluent and urban river was observed.

Considering the dangerous effects of hospital wastewater, various physical, chemical and biological solutions have so far been proposed and examined. Examples of physical methods studied for hospital sewage treatment are as membrane technology (Sancho et al. [50] and absorbance with active carbon [16]. It has been pointed out that these physical methods merely transfer contaminants from one environment to another without destroying contaminants. Examples of chemical methods used in hospital sewage treatment are fenton oxidation [60], Multi-Stage Ozone Injection [21], and ozonation $/ \mathrm{H}_{2} \mathrm{O}_{2}$, UV photolysis $/ \mathrm{H}_{2} \mathrm{O}_{2}$, photo-Fenton [7]. These ways are quite costly and are not ecofriendly due to involvement of harmful chemicals.

Examples of biological methods used in hospital wastewater treatment are fungal-reactors [22, 24], conventional activated sludge reactor [12], MBBR [19], MBR [57], and microalgae [23]. These methods are used largely in order to low costs. Due to low efficiency, however, they need to be strengthened through combination of biological and chemical methods. For example, it is possible to use the combination of photocatalyst $\mathrm{TiO}_{2}, \mathrm{UV}$ and $\mathrm{H}_{2} \mathrm{O}_{2}$; and sequencing batch reactor (SBR) [9]. The composition of Fenton-SBR [9] has been investigated for treatment of antibiotic-containing wastewater. Although this strategy is less expensive than the chemical method alone, it is environmentally harmful and more expensive than the biological method.

Treatment efficiency prediction of the different reactors and the prediction of environmental phenomena have been studied in recent years. Response surface methodology is one of the most applied methods that can be used for prediction $[6,8,18,31-34,53,54]$.

With regard to the above facts, biological treatment of hospital wastewater has minimum cost and high efficiency and it is the best solution. Accordingly, this study proposed a new biological reactor that called SSBMBR for hospital sewage treatment. In addition, the retention time can be customized in the new proposed reactor. Microorganisms

Table 1 Characteristics of the hospital wastewater

\begin{tabular}{ll}
\hline Parameter & Average $(\mathrm{mg} / \mathrm{L})$ \\
\hline $\mathrm{COD}$ & 663 \\
$\mathrm{TOC}$ & 180 \\
$\mathrm{NH}_{4}-\mathrm{N}$ & 13 \\
Total phosphorus & 8.6 \\
\hline
\end{tabular}

in this new reactor has highly resistant to shock because of biofilm mechanism [26]. Also, in this research for the first time, several reactors were used in series to achieve the desired efficiency in a completely environmentally friendly procedure. In this study, the experimental results were analyzed statistically through ANOVA. Also, a mathematical model provided to predict efficiency using response surface methodology (RSM).

\section{Materials and Methods}

\subsection{Wastewater}

This study involved a real-life hospital wastewater with characteristics displayed in Table 1.

\subsection{Structure of each reactor}

The new proposed reactor consisted of seven reactors that connected to each other in serail mode. For each one of the seven reactors, the MBBR was used, those seven reactor were completely similar to each other. The total volume of each reactor was $5.7 \mathrm{~L}$, while the height of each bioreactor was $70 \mathrm{~cm}$. The reactors were made of Plexiglas so the contents were easily visible. The other specifications of each reactor have been given in Table 2 .

One of the main components of each MBBR is the media used in it. For this purpose, Bee Cell 2000 media was used, which offers greater specific surface than other conventional media. The appearance of media and their characteristics can be seen in Fig. 1 and Table 3 .

Another important component of the reactors was aeration, which supplied the oxygen needed for biologic

Table 2 Specifications of each bioreactor

\begin{tabular}{ll}
\hline Parameter & Level \\
\hline Wall thickness $(\mathrm{mm})$ & 4 \\
Inner diameter $(\mathrm{cm})$ & 10 \\
Bioreactor height $(\mathrm{cm})$ & 70 \\
Total volume of each pilot $(\mathrm{L})$ & $7 / 5$ \\
\hline
\end{tabular}

Fig. 1 Bee Cell 2000 (the used media)

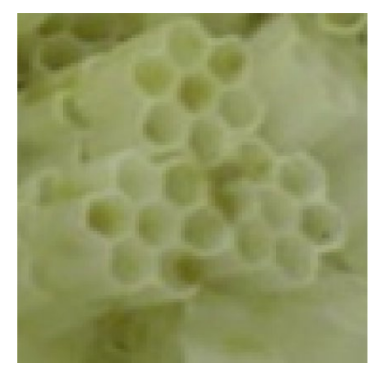


Table 3 Characteristics of the media (Bee Cell 2000)

\begin{tabular}{ll}
\hline Parameter & Level \\
\hline Composition of media & $\begin{array}{l}\text { High density } \\
\text { poly ethylene } \\
\text { (HDPE) }\end{array}$ \\
& 0.95 \\
Density $\left(\mathrm{g} / \mathrm{cm}^{3}\right)$ & 650 \\
Specific surface $\left(\mathrm{m}^{2} / \mathrm{m}^{3}\right)$ & 857 \\
Effective surface of one media $\left(\mathrm{mm}^{2} /\right.$ piece) & 1800 \\
Total surface of one media $\left(\mathrm{mm}^{2} /\right.$ piece) & \\
\hline
\end{tabular}

reactions and mixing of media throughout the reactor. The aeration system included air pumps, hoses and aeration rocks. The commercial name of the pumps was Sonic 9908. Moreover, the outlet compressed air from the pumps was transferred through the hose to the aeration rocks placed at the bottom of the reactor. Additionally, the aeration took place at a rate of $33.3 \mathrm{~L}$ per minute per liter of liquid.

\subsection{Biofilm formation on media}

In moving-bed biofilm reactors, the main role in treatment were related to microorganisms attached to the media. At the first stage, microorganisms were prepared from the hospital treatment plant so these microorganisms were compatible with the wastewater. Then, the media were inserted into the reactor, letting the microorganisms grow and form biofilm on the media. So as to remove the microorganisms suspended in the treatment, the wastewater were slowly discharged from the lowest reactor outlet at a slow rate. Subsequently, the reactors were filled and the main experiments were carried out.

\subsection{Transfer of wastewater between reactors at each run}

After biofilm formation on media, the reactors were connected to each other and the following steps were done at each alteration in the influent concentration (Fig. 2).

Step 1 At first, each reactor was filled (to useful volume) from influent wastewater. Following this, aeration took place until the retention time was completed. Then, the aerator was switched off for $30 \mathrm{~min}$ for separating media and sludge from wastewater. After that, the wastewater of Reactor 7 was discharged and sampled for testing. The wastewater of Reactor 6 was transferred to Reactor 7, and Reactor 5 was transferred to Reactor 6 , and the wastewater of Reactor $(n-1)$ was transferred to Reactor (n). Once again, Reactor 1 was filled by wastewater with initial concentration.

Step 2 The previous step was repeated by aeration until the system reaches steady state. The efficiency of steady state for each initial concentration have been presented in this study.

\subsection{RSM and independent and dependent variables}

In this study, a multivariable statistical analysis served to develop a new model and identify the optimal conditions

Fig. 2 Three-dimensional image of the reactor

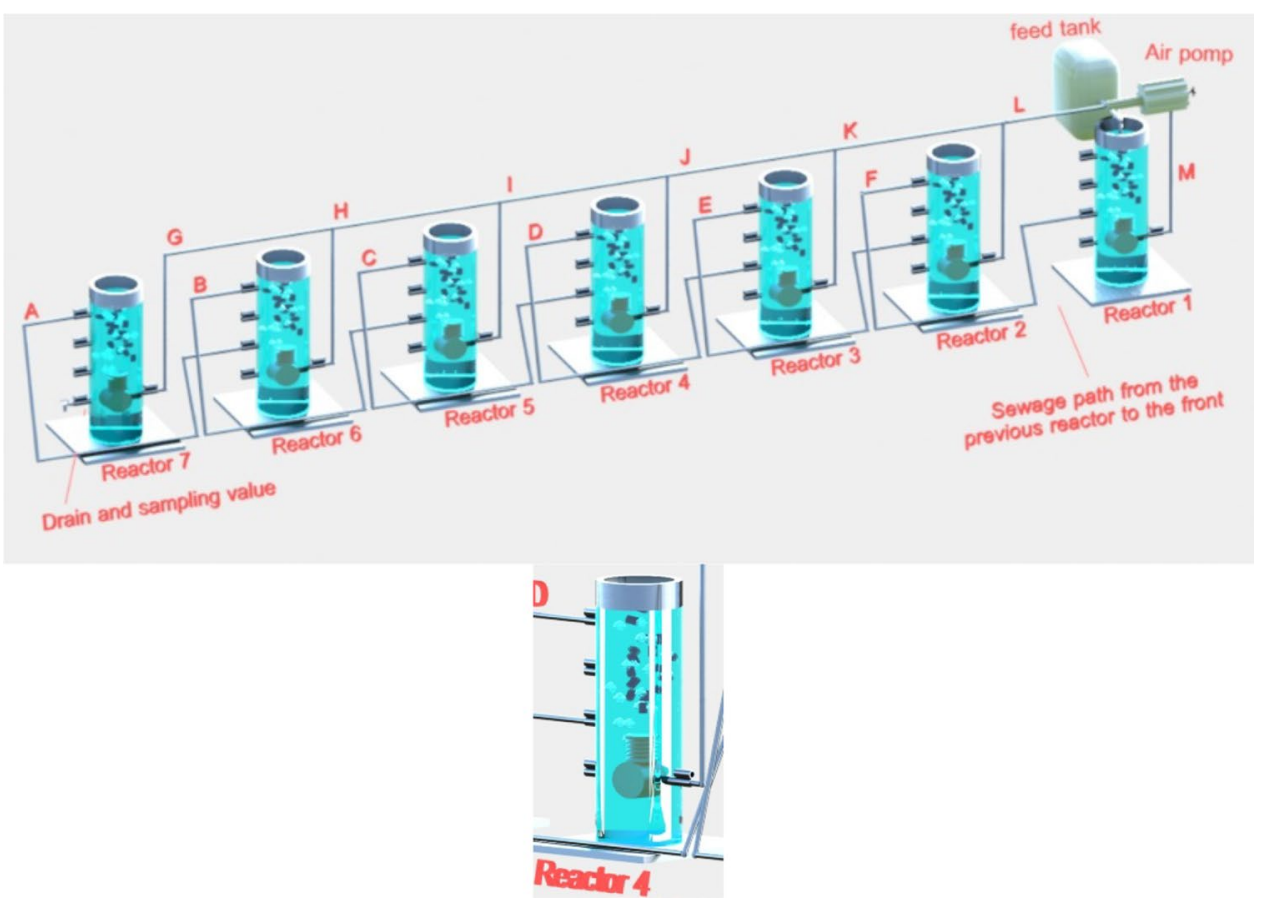


for treatment of hospital wastewater in the SSBMBR. For that purpose, several tests were designed through RSM.

RSM is a mathematical method defining a relationship between several independent variables and a dependent variable. Previous studies have demonstrated that RSM is an acceptable method in comparison with other methods [17]. In this research, Design-Expert 7.0.0 was employed to design tests and analyze the results. The software suggested a total of 20 tests considering the details provided in Table 4. In this table, the columns display the independent variables and their units of measurement, while the subsequent columns list the values of variables in Levels 1 and -1 separately. The last column displays the standard deviation in each variable. Values of three independent variables (retention time, pollutant loading and media filling percentage of each reactor) for each experiment are presented in Table 5.

\subsection{Reactor control and periodic tests}

The $\mathrm{pH}$ was measured on a periodic basis and kept steady at all stages within the range of 6.8-7.2. Moreover, the bioreactor temperature was within $21-25^{\circ} \mathrm{C}$.

\subsection{Reference for tests}

All tests were carried out based on instructions provided in Standard Methods for Examination of Water and Wastewater [13].

\section{Results and discussion}

In this study, analyzing of the experimental results was done by using of RSM. Furthermore, a mathematical model was used to predict efficiency through RSM. The interaction of independent variables on each other was the other result of model. The effective independent variables were retention time, pollutant loading and media filling percentage, whose effects of independent variables on COD removal efficiency were assessed. Table 6 provides the results of all experiments.
Table 5 RSM main experiment details

\begin{tabular}{lllr}
\hline Run & $\begin{array}{l}\text { Retention } \\
\text { time }(\mathrm{h})\end{array}$ & $\begin{array}{l}\text { Pollutant loading } \\
(\text { kgCOD/kgMLSS) }\end{array}$ & Media filling (\%) \\
\hline 1 & 25.00 & 0.25 & 0.30 \\
2 & 37.50 & 0.30 & 70.23 \\
3 & 50.00 & 0.25 & 0.30 \\
4 & 25.00 & 0.35 & 0.60 \\
5 & 16.48 & 0.30 & 0.45 \\
6 & 37.50 & 0.30 & 0.45 \\
7 & 50.00 & 0.35 & 0.30 \\
8 & 58.52 & 0.30 & 0.45 \\
9 & 37.50 & 0.30 & 0.45 \\
10 & 50.00 & 0.35 & 0.60 \\
11 & 25.00 & 0.35 & 0.30 \\
12 & 37.50 & 0.30 & 19.77 \\
13 & 37.50 & 0.30 & 0.45 \\
14 & 37.50 & 0.30 & 0.45 \\
15 & 37.50 & 0.30 & 0.45 \\
16 & 50.00 & 0.25 & 0.60 \\
17 & 37.50 & 0.38 & 0.45 \\
18 & 25.00 & 0.25 & 0.60 \\
19 & 37.50 & 0.22 & 0.45 \\
20 & 37.50 & 0.30 & 0.45 \\
\hline & & &
\end{tabular}

\subsection{Simultaneous effect of parameters}

Simultaneous effect of every two parameters was investigated in this part. This section explores several 3D graphs, where in each graph; one variable is constant while the simultaneous relationship between the other two variables and COD removal efficiency is evaluated.

\subsubsection{Simultaneous effect of retention time and pollutant loading}

Figure 3 presents the simultaneous effect of retention time and pollutant loading on COD removal efficiency at $45 \%$ of media filling ratio. According to Fig. 3 , the COD removal efficiency was $38 \%$ at a retention time of $16.48 \mathrm{~h}$ and pollutant loading of $0.3 \mathrm{kgCOD} / \mathrm{kgMLSS}$. It was $58 \%$ at a retention time of $37.5 \mathrm{~h}$ and pollutant loading of $0.38 \mathrm{kgCOD} / \mathrm{kgMLSS}$. It was $70 \%$ at a retention time of $37.5 \mathrm{~h}$ and pollutant loading of $0.3 \mathrm{kgCOD} / \mathrm{kgMLSS}$. It

Table 4 Summary of model design based on independent variables

\begin{tabular}{|c|c|c|c|c|c|c|c|c|c|}
\hline Factor & Name & Unit & Type & Low actual & High actual & Low coded & High coded & Mean & SD \\
\hline A & Retention time & $\mathrm{h}$ & Numeric & 25.00 & 50.00 & -1.000 & 1.000 & 37.500 & 10.329 \\
\hline B & Pollutant loading & $\mathrm{kgCOD} / \mathrm{kgMLSS}$ & Numeric & 0.25 & 0.35 & -1.000 & 1.000 & 0.300 & 0.041 \\
\hline C & Media filling percent & $\%$ & Numeric & 30.00 & 60.00 & -1.000 & 1.000 & 45.000 & 12.395 \\
\hline
\end{tabular}


Table 6 Results of all experiments

\begin{tabular}{lllrl}
\hline Run & $\begin{array}{l}\text { Reten- } \\
\text { tion time } \\
\text { (h) }\end{array}$ & $\begin{array}{l}\text { Pollutant loading } \\
\text { (kgCOD/kgMLSS) }\end{array}$ & Media filling (\%) & $\begin{array}{l}\text { Removal } \\
\text { efficient } \\
(\%)\end{array}$ \\
\hline 1 & 25.00 & 0.25 & 0.30 & 60 \\
2 & 37.50 & 0.30 & 70.23 & 78 \\
3 & 50.00 & 0.25 & 0.30 & 92 \\
4 & 25.00 & 0.35 & 0.60 & 41 \\
5 & 16.48 & 0.30 & 0.45 & 38 \\
6 & 37.50 & 0.30 & 0.45 & 70 \\
7 & 50.00 & 0.35 & 0.30 & 74 \\
8 & 58.52 & 0.30 & 0.45 & 86 \\
9 & 37.50 & 0.30 & 0.45 & 70 \\
10 & 50.00 & 0.35 & 0.60 & 79 \\
11 & 25.00 & 0.35 & 0.30 & 32 \\
12 & 37.50 & 0.30 & 19.77 & 63 \\
13 & 37.50 & 0.30 & 0.45 & 70 \\
14 & 37.50 & 0.30 & 0.45 & 70 \\
15 & 37.50 & 0.30 & 0.45 & 70 \\
16 & 50.00 & 0.25 & 0.60 & 95 \\
17 & 37.50 & 0.38 & 0.45 & 58 \\
18 & 25.00 & 0.25 & 0.60 & 73 \\
19 & 37.50 & 0.22 & 0.45 & 91 \\
20 & 37.50 & 0.30 & 0.45 & 70 \\
\hline & & & &
\end{tabular}

was $86 \%$ at a retention time of $58.52 \mathrm{~h}$ and pollutant loading of $0.3 \mathrm{kgCOD} / \mathrm{kgMLSS}$. Finally, the COD removal efficiency was $91 \%$ at a retention time of $37.5 \mathrm{~h}$ and pollutant loading of $0.22 \mathrm{kgCOD} / \mathrm{kgMLSS}$. According to the results, increasing of retention time and decreasing of pollutant loading caused to increasing of COD removal efficiency.

\subsubsection{Simultaneous effect of retention time and media filling percentage}

Figure 4 displays the simultaneous effect of retention time and media filling percentage on COD removal efficiency, where pollutant loading was assumed to be constant at 0.3 $\mathrm{kgCOD} / \mathrm{kgMLSS}$. The COD removal efficiency was obtained $38 \%$ at a retention time of $16.48 \mathrm{~h}$ and media filling percentage of $45 \%$. Moreover, the COD removal efficiency was obtained $63 \%$ at a retention time of $37.5 \mathrm{~h}$ and media filling percentage of $19.77 \%$. It was $70 \%$ at a retention time of $37.5 \mathrm{~h}$ and media filling percentage of $45 \%$. It was $78 \%$ at a retention time of $37.5 \mathrm{~h}$ and media filling percentage of $70.23 \%$. Finally, it was $86 \%$ at a retention time of $58.52 \mathrm{~h}$ and media filling percentage of $45 \%$. Based on the results, retention time and media filling percentage had same effect on COD removal efficiency and increasing in this two parameters caused to increasing COD removal efficiency.

\subsubsection{Simultaneous effect of pollutant loading and media filling percentage}

Figure 5 shows the COD removal efficiency at a constant retention time of $37.5 \mathrm{~h}$ and simultaneous variations in pollutant loading and media filling percentage. The COD removal efficiency was obtained $58 \%$ at a pollutant loading of $0.38 \mathrm{kgCOD} / \mathrm{kgMLSS}$ and media filling percentage of $45 \%$. Also, the removal efficiency was $63 \%$ at a pollutant loading of $0.3 \mathrm{kgCOD} / \mathrm{kgMLSS}$ and media filling
Fig. 3 Simultaneous effect of retention time and pollutant loading on COD removal efficiency (media filling percentage $=45.00 \%)$
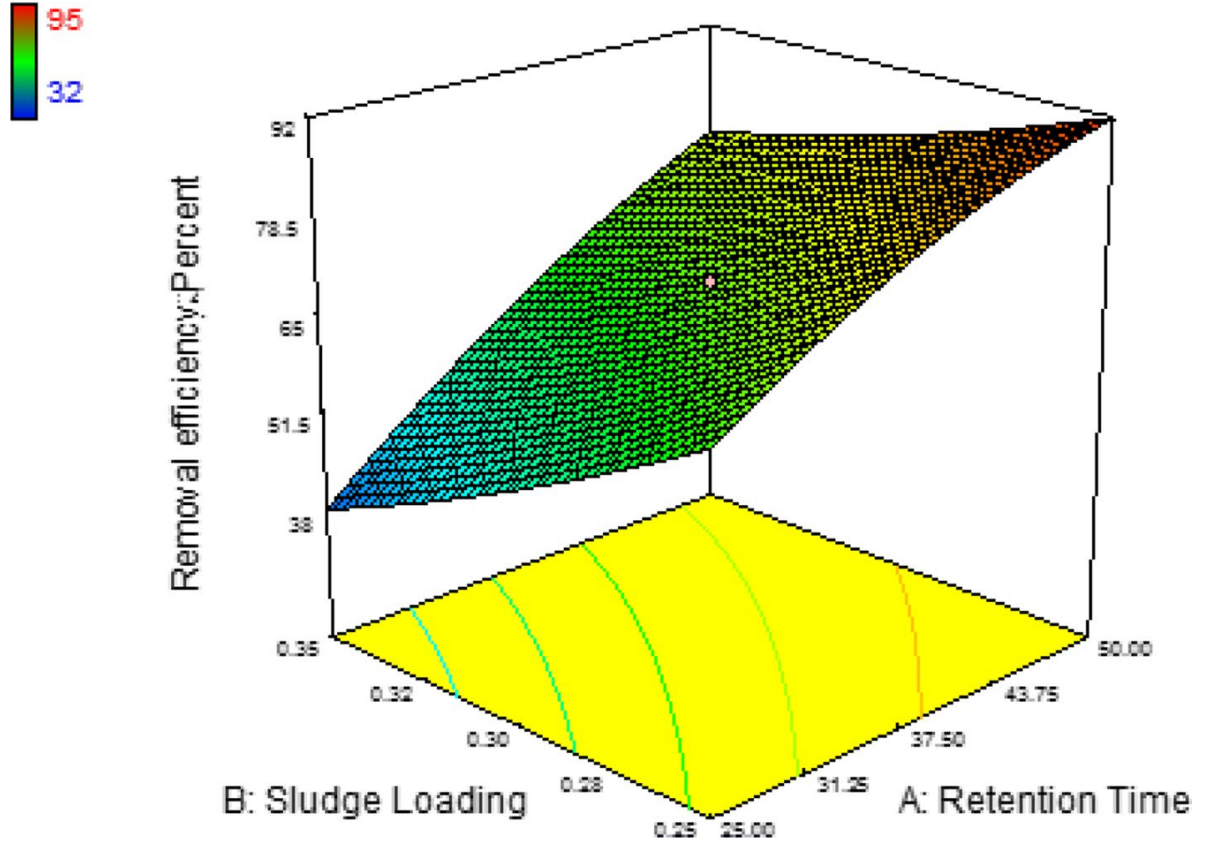

SN Applied Sciences A SPRINGER NATURE journa 
Fig. 4 Simultaneous effect of media filling percentage and retention time on COD removal efficiency (pollutant loading $=0.30 \mathrm{kgCOD} / \mathrm{kgMLSS}$ )

Fig. 5 Simultaneous effect of media filling percentage and pollutant loading on COD removal efficiency (retention time $=37.50 \mathrm{~h}$ )
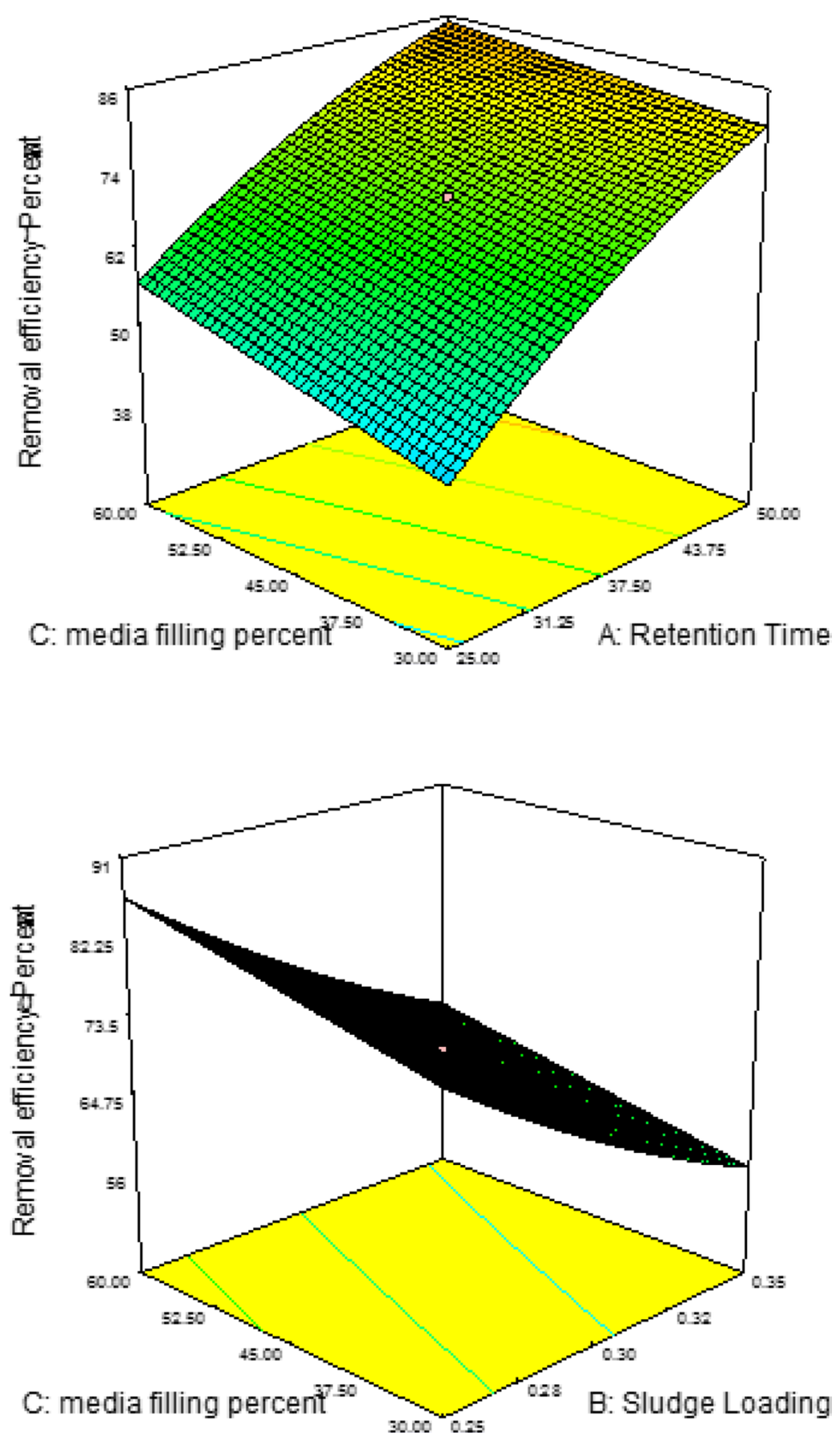

percentage of $19.77 \%$. The COD removal efficiency was $70 \%$ at a pollutant loading of $0.3 \mathrm{kgCOD} / \mathrm{kgMLSS}$ and media filling percentage of $45 \%$. It was $78 \%$ at a pollutant loading of $0.3 \mathrm{kgCOD} / \mathrm{kgMLSS}$ and media filling percentage of $70.23 \%$. Finally, it was $91 \%$ at a pollutant loading of $0.22 \mathrm{kgCOD} / \mathrm{kgMLSS}$ and media filling percentage of $45 \%$. The results shows, this two parameters hasn't same effect on COD removal efficiency, so that, COD removal efficiency increased by increasing in retention time and decreasing in pollutant loading.

\subsection{Individual effect of parameters}

Individual effects of parameters were investigated in this part. This section contains several 1D graphs, where two variables are constant while the effect of variations in the third variable on the COD removal efficiency is evaluated. 


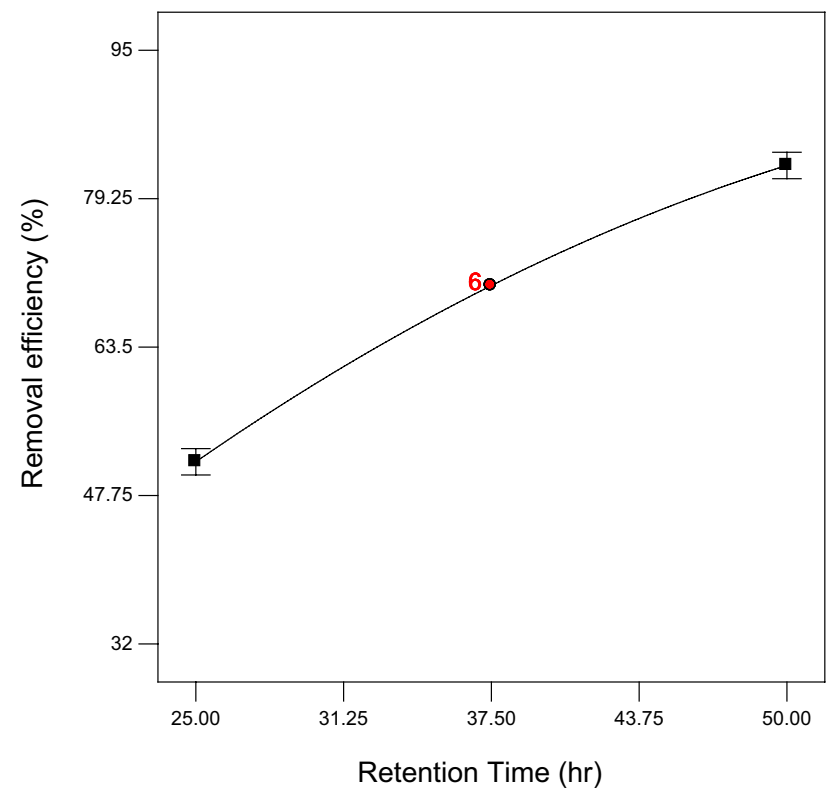

Fig. 6 The effect of variations in retention time on COD removal efficiency (pollutant loading $=0.30 \mathrm{kgCOD} / \mathrm{kgMLSS}$, media filling percentage $=45.00 \%$ )

\subsubsection{Effect of retention time}

In Fig. 6, the effect of variations in retention time on COD removal efficiency was presented at constant values for media filling percentage (45\%) and pollutant loading $(0.3 \mathrm{kgCOD} / \mathrm{kgMLSS})$. The COD removal efficiency was obtained $38 \%$ at a retention time of $16.48 \mathrm{~h}$, and $70 \%$ and $86 \%$ at retention times of $37.5 \mathrm{~h}$ and $58.52 \mathrm{~h}$, respectively. According to the results, retention time has direct effect on the COD removal efficiency.

\subsubsection{Effect of pollutant loading}

Figure 7 displays COD removal efficiency under variations in pollutant loading and at a constant retention time ( $37.5 \mathrm{~h}$ ) and media filling percentage (45\%). Based on Fig. 7, the inverse effect of pollutant loading on COD removal efficiency can be concluded, so that the COD removal efficiency was $58 \%$ at a pollutant loading of 0.38 $\mathrm{kgCOD} / \mathrm{kgMLSS}, 70 \%$ at a pollutant loading of $0.3 \mathrm{kgCOD} /$ $\mathrm{kgMLSS}$, and finally $91 \%$ at a pollutant loading of 0.22 $\mathrm{kgCOD} / \mathrm{kgMLSS}$.

\subsubsection{Effect of media filling percentage}

Figure 8 presents the values of COD removal efficiency under variations in media filling percentage and at a constant retention time $(37.5 \mathrm{~h})$ and pollutant loading $(0.3$ $\mathrm{kgCOD} / \mathrm{kgMLSS}$ ). The COD removal efficiency was $63 \%$ at

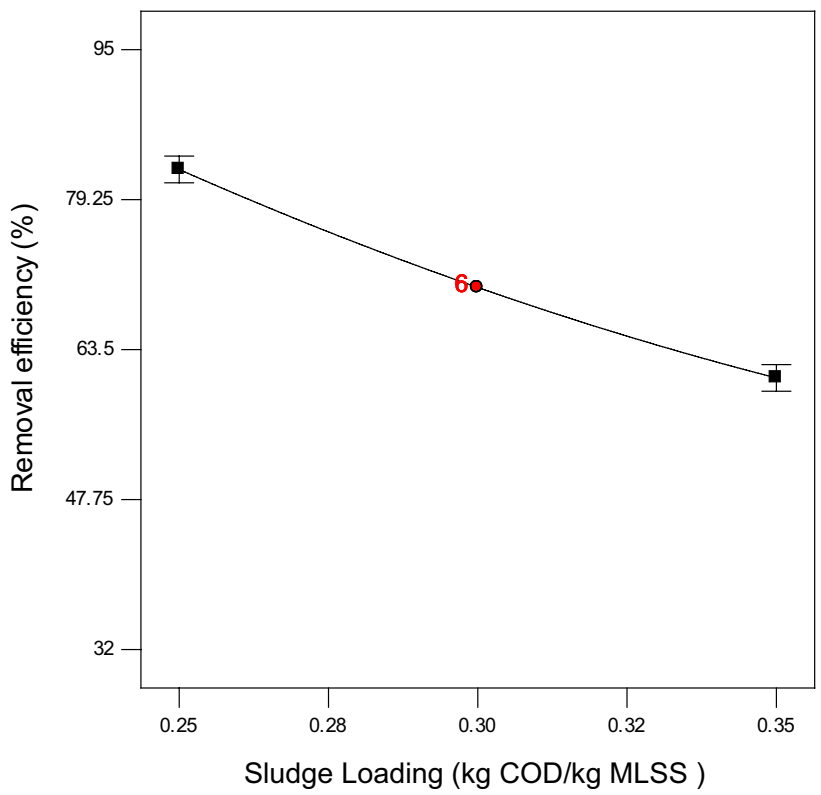

Fig. 7 Effect of Variations in Pollutant loading on COD Removal Efficiency (Retention Time $=37.50 \mathrm{~h}$, Media Filling Percentage $=45.00 \%)$

a media filling percentage of $19.77 \%$, and $78 \%$ at a media filling percentage of $70.23 \%$.

Similar studies on the effect of different COD loadings on biological phosphorus removal demonstrated that removal efficiency decreases by increasing in loadings [59].

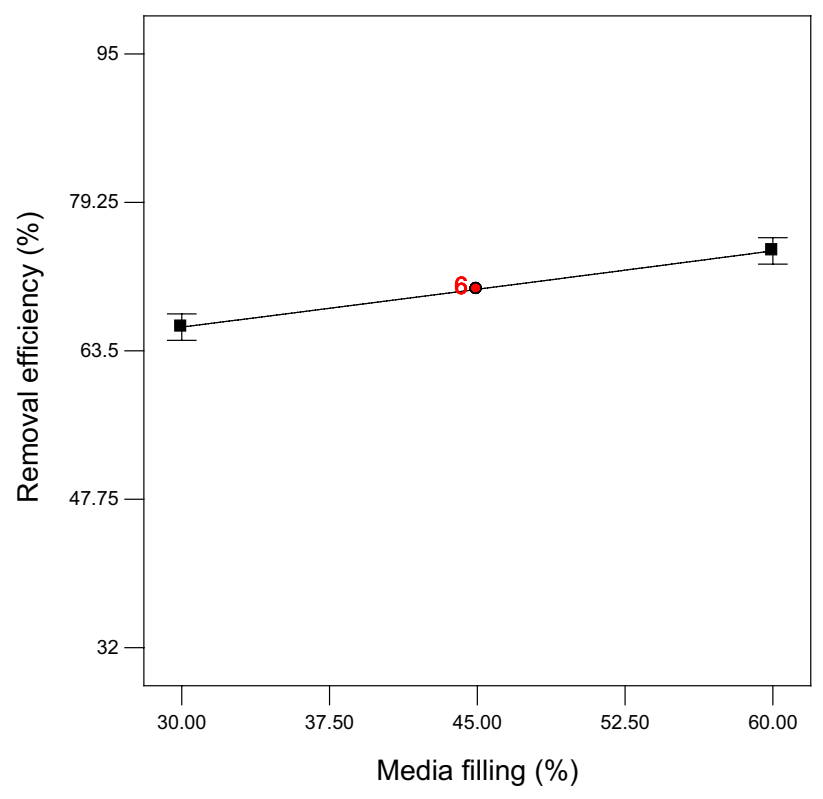

Fig. 8 Effect of variations in media filling percentage on COD removal efficiency (retention time $=37.50 \mathrm{~h}$, pollutant loading $=0.30 \mathrm{kgCOD} / \mathrm{kgMLSS}$ ) 


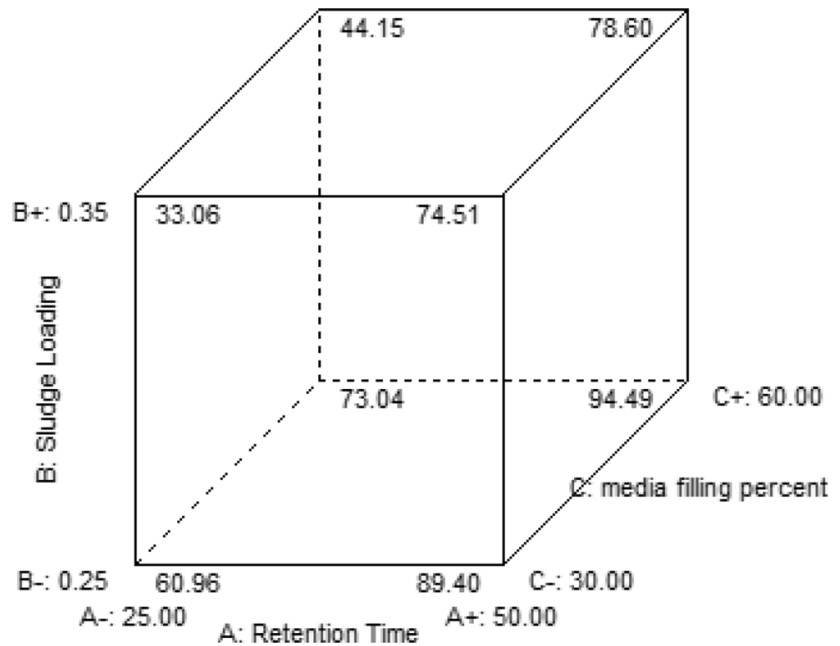

Fig. 9 Simultaneous effect of three variables on COD removal efficiency

In previous studies, a polyurethane sponge was employed as a biofilm carrier in a MBBR for domestic synthetic wastewater treatment. The results suggested, filling percentage had a simultaneous positive effect on the removal of total nitrogen (TN) as well as on nitrification and denitrification [61].

\subsection{Effects of all parameters}

Figure 9 illustrates the simultaneous effect of retention time, pollutant loading and media filling percentage on COD removal efficiency. The lowest COD removal efficiency was $32 \%$ at a retention time of $25 \mathrm{~h}$, pollutant loading of $0.35 \mathrm{kgCOD} / \mathrm{kgMLSS}$, and media filling percentage of $30 \%$. Moreover, the highest COD removal efficiency was $95 \%$ at a retention time of $50 \mathrm{~h}$, pollutant loading of $0.25 \mathrm{kgCOD} /$ $\mathrm{kgMLSS}$ and media filling percentage of $60 \%$.

\subsection{Interaction effects}

Interaction effects of parameters were investigated in this part. Every graph present the interactive pair-wise effect of variables. Effects of variations in these variables are either synergistic or inverse.

\subsubsection{Interaction between retention time and media filling percentage}

Figure 10, displays the interactive effect of retention time and media filling percentage on COD removal efficiency (at a constant pollutant loading of $0.3 \mathrm{kgCOD} /$ kgMLSS,). In the shortest retention time (25 h), when media filling percentage increased from 30 to $60 \%$, COD removal efficiency increased from about 45 to $55 \%$. At

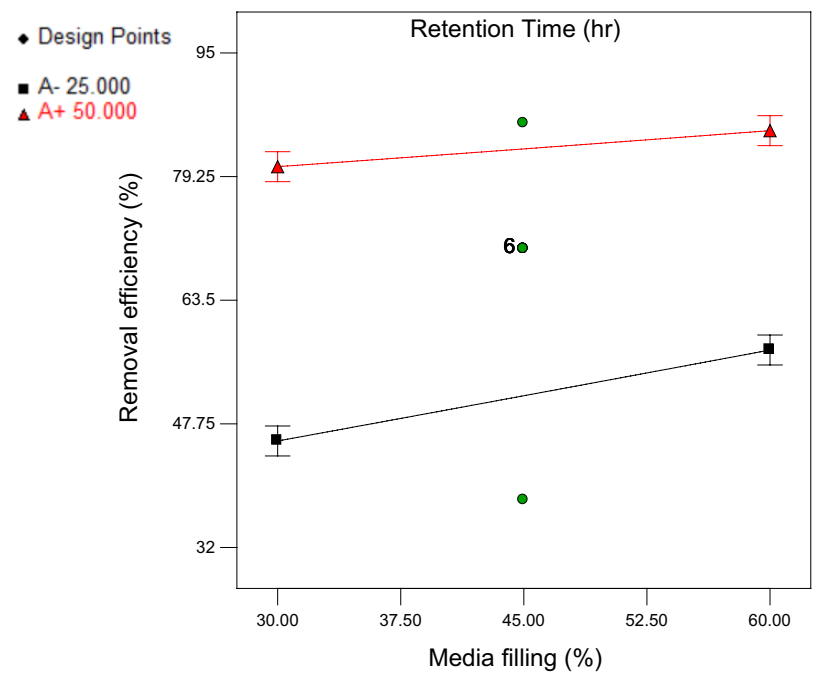

Fig. 10 Interactive effect of media filling percentage and retention time on COD removal efficiency (pollutant loading $=0.30 \mathrm{kgCOD} /$ kgMLSS)

the maximum retention time of $50 \mathrm{~h}$, when media filling percent increased from 30 to 60 , COD removal efficiency increased from about 80 to $85 \%$. Therefore, there was an evident synergistic effect between retention time and media filling percentage. Since the increase in COD removal efficiency at the minimum retention time (25 h) had a similar trend to that at the maximum retention time $(50 \mathrm{~h})$ when increasing media filling percentage from 30 to $60 \%$, it can be argued that two independent variables, retention time and media filling percentage, had significantly positive effects on each other.

\subsubsection{Interaction between retention time and pollutant loading}

Figure 11 shows the interactive effect of retention time and pollutant loading on COD removal efficiency at a constant media filling percentage of $45 \%$. At the maximum pollutant loading of $0.35 \mathrm{kgCOD} / \mathrm{kgMLSS}$, the COD removal efficiency increased from about 35 to $75 \%$ within a retention time range of $25-50 \mathrm{~h}$. This indicated a synergistic trend. As shown in the figure, the increase in COD removal efficiency at the maximum pollutant loading is greater than that at the minimum value of this variable. Therefore, it can be argued that there was a significant relationship between retention time and pollutant loading.

\subsubsection{Interaction between media filling percentage and pollutant loading}

Figure 12 shows the interactive effect of media filling percentage and pollutant loading on COD removal 


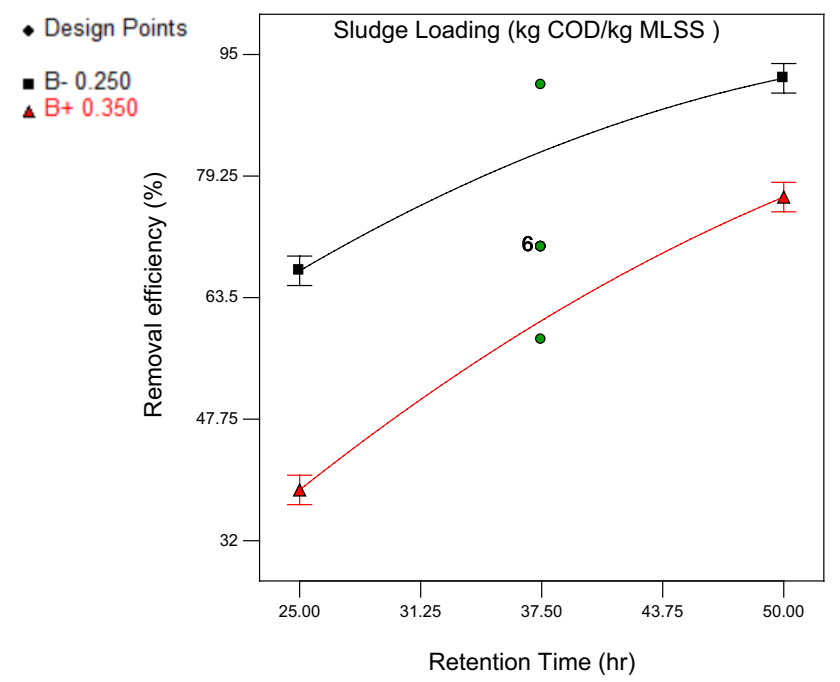

Fig. 11 Interactive effect of pollutant loading and retention time on COD removal efficiency (media filling percent $=45.00 \%$ )

efficiency at a constant retention time of $37.5 \mathrm{~h}$. At the minimum media filling percentage of $30 \%$, pollutant loading increased from about $0.25 \mathrm{kgCOD} / \mathrm{kgMLSS}$ to $0.35 \mathrm{kgCOD} / \mathrm{kgMLSS}$, where the COD removal efficiency dropped from about $78 \%$ to $60 \%$. At the maximum media filling percentage of $60 \%$, the COD removal efficiency decreased from about $87 \%$ to $67 \%$ with the same variation in pollutant loading. Therefore, the reduction of COD removal efficiency due to increased pollutant loading was identical at different media filling percentages. Therefore, it can be argued that there was no significant relationship between the two independent variables (media filling percentage and pollutant loading).

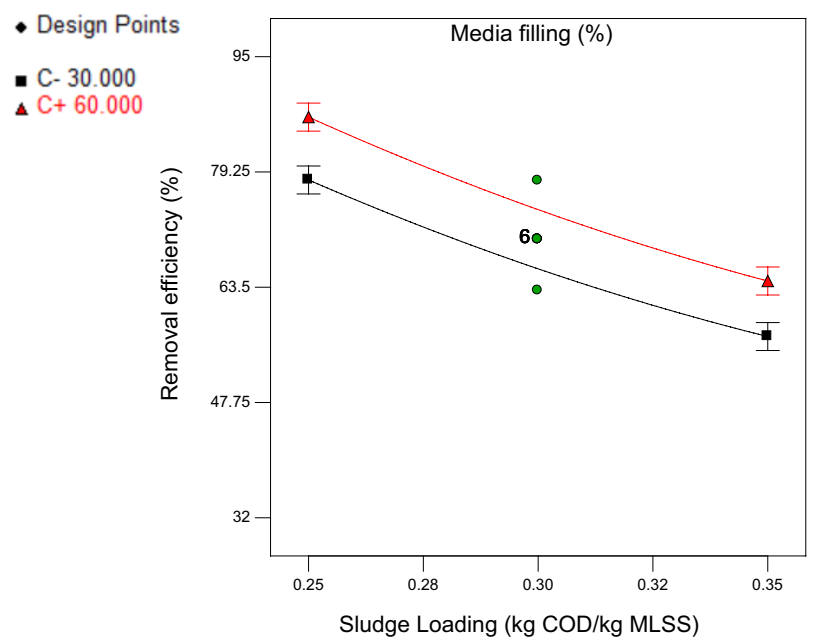

Fig. 12 Interactive effect of media filling percentage and pollutant loading on COD removal efficiency (retention time $=37.50 \mathrm{~h}$.)

\subsection{Mathematical model}

The mathematical model was presented based on the response surface methodology. The removal efficiency was changed by $1.5,-745.8$, and +0.7 units for a unit increase in retention time, pollutant load, and media filling percentage, respectively. It was changed by +5.2 units for a unit increase in the retention time and pollutant load, by -0.00933 units for a unit increase in the retention time and media filling percentage, by -0.33 units for a unit increase in the pollutant loading and media filling percentage, by -0.019 and 578.2 units for a unit increase in the retention time squared and the pollutant load squared, respectively, and by $1.39 \times 10^{-4}$ units for a unit increase in the media filling percentage squared.

$$
\begin{aligned}
& \text { Removal Efficiency Percent }=+140.20822+1.54531 * \text { Retention Time }-745.86197 \\
& * \text { Pollutant loading }+0.70707 * \text { Media Filling Percent }+5.20000 * \text { Retention Time } \\
& * \text { Pollutant loading }-0.00933333 * \text { Retention Time } * \text { Media Filling Percent }-0.33333 \\
& * \text { Pollutant loading } * \text { Media Filling Percent }-0.019033 * \text { Retention Time }^{2} \\
& \quad+578.20919 * \text { Pollutant loading } \\
&
\end{aligned}
$$


Table 7 The results of ANOVA based on RSM

\begin{tabular}{lclclc}
\hline Source & Sum of squares & $\mathrm{df}$ & Means squares & F value & $P$ value prob. $>\mathrm{F}$ \\
\hline Model & 5517.48 & 9 & 613.05 & 151.31 & $<0.0001$ \\
A-retention time & 3376.13 & 1 & 3376.13 & 833.25 & $<0.0001$ \\
B-pollutant loading & 1636.54 & 1 & 1636.54 & 403.91 & $<0.0001$ \\
C-media filling & 223.33 & 1 & 223.33 & 55.12 & $<0.0001$ \\
AB & 84.50 & 1 & 84.50 & 20.86 & 0.0010 \\
AC & 24.50 & 1 & 24.50 & 6.05 & 0.0337 \\
BC & 0.7327 & 0.12 & 0.50 & 1 & 0.50 \\
$A^{2}$ & 0.0002 & 31.46 & 127.45 & 1 & 127.45 \\
$B^{2}$ & 30.11 & 1 & 30.11 & 7.43 & 0.0213 \\
$C^{2}$ & 0.014 & 1 & 0.014 & $3.487 E-003$ & 0.9541 \\
Residual & 40.52 & 10 & 4.05 & & \\
Lack of fit & 40.52 & 5 & 8.10 & & \\
Pure error & 0.000 & 5 & 0.000 & & \\
Core total & 5558.80 & 19 & & &
\end{tabular}

Regarding the above relationship and based on the direct first-order effect of factors, it can be argued that the effect of variations in pollutant load on variations in removal efficiency was greater than that of the other two factors. In general, the effects of three variables can be described as follows:

Pollutant loading $>$ Retention Time $>$ Media Filling Percentage

\subsection{Analysis of Variance}

Analysis of variance (ANOVA) is a method by which, variations or dispersions in a dataset are divided into different components [20] and show the significance of parameters. Table 7, displays the results of ANOVA. An important column in the table displays $P$ value. When $P$-value is lower than 0.025 , i.e. the effect of parameter is significant at a $95 \%$ significance.

\subsection{Optimal conditions}

According to the results obtained by RSM, the optimum conditions to achieve the maximum COD removal efficiency were at $46.59 \mathrm{~h}$ of retention time, $0.34 \mathrm{kgCOD} /$ kgMLSS of pollutant loading, and $42.24 \%$ of media filling percentage. In the optimum conditions, mathematical model presented COD removal efficiency of $73.47 \%$. Experiments in the laboratory showed an efficiency of $76.47 \%$ in mentioned conditions.

\section{Conclusion}

Given the significant existence of pollutants in hospital wastewater, a variety of techniques have been adopted to remove pollutants. This study examined the biological removal of such hazardous pollutants in a SSBMBR. The capability of SSBMBR in treatment of hospital wastewater was confirmed in this research. Also, in this research, the removal efficiency is predicted by a mathematical model based on RSM, where the interactive effect of independent variables on each other as well as on the dependent variable is verified. Retention time, pollutant loading and media filling percentage were effective independent variables on COD removal efficiency. According to the results, pollutant loading variation have the greatest effect on removal efficiency and the COD removal efficiency increased from $58 \%$ to $91 \%$ by increasing pollutant loading from $0.22 \mathrm{kgCOD} / \mathrm{kgMLSS}$ to $0.38 \mathrm{kgCOD} / \mathrm{kgMLSS}$, at constant values of retention time $(37.5 \mathrm{~h})$ and media filling percentage $(45 \%)$. Furthermore, the removal efficiency increased from $38 \%$ to $86 \%$ with an increase in retention time from 16.48 to $58.52 \mathrm{~h}$ and at constant values of $0.3 \mathrm{kgCOD} / \mathrm{kgMLSS}$ and $45 \%$ for pollutant loading and media filling percentage, respectively. According to the results, this reactor can prove to be a good alternative to the conventional bioreactors in hospital wastewater treatment.

\section{Compliance with ethical standards}

Conflict of interest The authors declare that the authors do not have conflict of interest. 


\section{References}

1. Abdel-Fatah MA, Shaarawy HH, Hawash SI (2019) Integrated treatment of municipal wastewater using advanced electro-membrane filtration system. SN Appl Sci. https://doi. org/10.1007/s42452-019-1178-9

2. Albuquerque MTD, lantunes MHR, Oliveira NP, Pelletier G (2019) Impact of sewage effluent discharges prediction using QUAL2Kw in a sensitive protected area: Portugal. SN Appl Sci. https://doi.org/10.1007/s42452-019-1095-y

3. Asadi P, Rad H, Qaderi F (2019) Comparison of Chlorella vulgaris and Chlorella sorokiniana pa.91 in post treatment of dairy wastewater treatment plant effluents. Environ Sci Pollut Res. https:// doi.org/10.1007/s11356-019-06051-8

4. Azizpour F, Qaderi F (2019) Optimization, modeling and uncertainty investigation of phenolic wastewater treatment by photocatalytic process in cascade reactor. Environ Dev Sustain. https ://doi.org/10.1007/s10668-019-00480-8

5. Babanezhad E, Amini Rad H, Hosseini Karimi SS, Qaderi F (2017) Investigating nitrogen removal using simultaneous nitrification-denitrification in transferring wastewater through collection networks with small-diameter pipes. Water Pract Technol 12:396-405. https://doi.org/10.2166/wpt.2017.044

6. Babanezhad E, Qaderi F, Salehi Ziri M (2018) Spatial modeling of groundwater quality based on using Schoeller diagram in GIS base: a case study of Khorramabad, Iran. Environ Earth Sci 77:339. https://doi.org/10.1007/s12665-018-7541-0

7. De Luna MDG, Veciana ML, Su CC, Lu MC (2012) Acetaminophen degradation by electro-Fenton and photoelectro-Fenton using a double cathode electrochemical cell. J Hazard Mater 217218:200-207. https://doi.org/10.1016/j.jhazmat.2012.03.018

8. Ebrahimi Ghadi M, Qaderi F, Babanezhad E (2018) Prediction of mortality resulted from $\mathrm{NO}_{2}$ concentration in Tehran by Air Q+ software and artificial neural network. Int J Environ Sci Technol. https://doi.org/10.1007/s13762-018-1818-4

9. Elmolla ES, Chaudhuri M (2011) The feasibility of using combined $\mathrm{TiO}_{2}$ photocatalysis-SBR process for antibiotic wastewater treatment. DES 272(1-3):218-224. https://doi. org/10.1016/j.desal.2011.01.020

10. Faghih Nasiri E, YousefiKebria D, Qaderi F (2018) An experimental study on the simultaneous phenol and chromium removal from water using titanium dioxide photocatalyst. Civ Eng J 4(3):585-593. https://doi.org/10.28991/cej-0309117

11. Faghih Nasiri E, Yousefi Kebria D, Qaderi F (2019) The degradation of phenol in water solution by immobilized $\mathrm{TiO}_{2}$ photocatalysis. J Civ Environ Eng 48(93):43-49

12. Ferrando-Climent L, Cruz-morató C, Marco-urrea E, Vicent T, Rodriguez-mozaz S, Barceló D (2015) Chemosphere non conventional biological treatment based on Trametes versicolor for the elimination of recalcitrant anticancer drugs in hospital wastewater. Chemosphere 136:9-19. https://doi. org/10.1016/j.chemosphere.2015.03.051

13. Greenberg AE, Clesceri LS, Eaton AD (2000) Standard methods for the examination of water and wastewater, 20th edn. American Public Health, Washington

14. Han N, Chen H, Reinhard M, Mao F, Gin KY (2016) Occurrence and removal of multiple classes of antibiotics and antimicrobial agents in biological wastewater treatment processes. Water Res 104:461-472

15. Hocquet D, Muller A, Bertrand X (2016) What happens in hospitals does not stay in hospitals: antibiotic-resistant bacteria in hospital wastewater systems. J Hosp Infect 93:395-402

16. Kalkan Ç, Yapsakli K, Mertoglu B, Tufan D, Saatci A (2011) Evaluation of biological activated carbon (BAC) process in wastewater treatment secondary effluent for reclamation purposes.
Desalination 265(1-3):266-273. https://doi.org/10.1016/j. desal.2010.07.060

17. Karami HR, Keyhani M, Mowla D (2016) Experimental analysis of drag reduction in the pipelines with response surface methodology. J Pet Sci Eng 138:104-112. https://doi.org/10.1016/j. petrol.2015.11.041

18. Khalegh R, Qaderi F (2019) Optimization of the effect of nanoparticle morphologies on the cost of dye wastewater treatment via ultrasonic/photocatalytic hybrid process. Appl Nanosci. https://doi.org/10.1007/s13204-019-00984-9

19. Kumar R, Ooi G, Hansen KMS, Litty K, Christensson M, Kragelund $C$ et al (2015) Biodegradation of pharmaceuticals in hospital wastewater by staged moving bed bio film reactors (MBBR). Water Res 83:293-302

20. Kuznetsova A, Christensen RHB, Bavay C, Brockhoff PB (2014) Automated mixed ANOVA modelling of sensory and consumer data. Food Qual Prefer 10:10. https://doi.org/10.1016/j.foodq ual.2014.08.004

21. Lago RM, Amorim CC, Marcelino RBP (2016) Multistage ozone and biological treatment system for real wastewater containing antibiotics. J Environ Manag 195:110-116

22. Lucas D, Badia-fabregat M, Vicent T, Caminal G, Rodríguezmozaz S, Balc JL (2016) Chemosphere fungal treatment for the removal of antibiotics and antibiotic resistance genes in veterinary hospital wastewater. Chemosphere 152:301-308

23. Matamoros V, García J, Bayona JM (2008) Organic micropollutant removal in a full-scale surface flow constructed wetland fed with secondary effluent. Water Res 42(3):653-660

24. Mir-tutusaus JA, Sarrà M, Caminal G (2016) Continuous treatment of non-sterile hospital wastewater by Trametes versicolor: how to increase fungal viability by means of operational strategies and pretreatments. J Hazard Mater 318:561-570

25. Pajoum Shariati F, Qaderi F, Haeri H (2019) Using moving bed biofilm reactor including kaldness media in treatment of wastewater containing light component petroleum. J Civ Environ Eng 49:1-19

26. Qaderi F, Ayati B, Ganjidoust H (2011) Role of moving bed biofilm reactor and sequencing batch reactor in biological degradation of formaldehyde wastewater. Iran J Environ Health Sci Eng 8(4):295-306

27. Qaderi F, Ayati B, Ganjidoust H (2012) Comparing the efficiency of MBBR and SBR in treating wastewater containing formaldehyde, Amirkabir. J Civ Eng 43(2):43-50

28. Qaderi F, Ayati B (2014) Comparison of MBBR and SBAR in treating toxic formaldehyde wastewater. J Civ Environ Eng 44(74):99-106

29. Qaderi F, Ayati B, Ganjidoust H, Sarraf-Mamoory R (2015) Investigation of kinetic and intermediate products of acid orange 7 removal by hybrid ozonation/photocatalytic processes. Modares J Civ Eng 15(2):79-89

30. Qaderi F, Ayati B, Ganjidoost H, Sarraf Mamoori R (2015) Treatment of wastewater containing acid orange 7 using ozonation process and determination of the intermediate by-products. J Water Wastewater 26(2):13-23

31. Qaderi F, Babanezhad E (2017) Prediction of the groundwater remediation costs for drinking use based on quality of water resource, using artificial neural network. J Clean Prod 161:840-849. https://doi.org/10.1016/j.jclepro.2017.05.187

32. Qaderi F, Sayahzadeh AH, Azizi M (2018) Efficiency optimization of petroleum wastewater treatment by using of serial moving bed biofilm reactors. J Clean Prod 192:665-677. https ://doi.org/10.1016/j.jclepro.2018.04.257

33. Qaderi F, Sayahzadeh AH, Azizpour F, Vosughi P (2018) Effciency modeling of serial stabilization ponds in treatment of phenolic wastewater by response surface methodology. 
Int J Environ Sci Technol. https://doi.org/10.1007/s1376 2-018-1816-6

34. Qaderi F, Asadi P, Tamadoni A, Azizi M (2018) Evaluation of sustainability of development in zone 22 of Tehran by ecological footprint method. Geogr Dev Iran J 16(50):231-245. https:// doi.org/10.22111/gdij.2018.3575

35. Qaderi F, Sayahzadeh AH, Ebrahimi Ghadi M (2019) Optimization of effective environmental parameters on Astrazon Red GTL removal by dominant species Bacillus and Aeromonas: in a concurrent culture study. J Mol Cell Res 32(1):1-15

36. Rita A, Ferro G, Vredenburg J, Yan M, Vieira L, Rizzo L et al (2013) Vancomycin resistant enterococci: from the hospital effluent to the urban wastewater treatment plant. Sci Total Environ 451:155-161

37. Sheikholeslami M (2017) Magnetic field influence on CuO$\mathrm{H} 2 \mathrm{O}$ nanofluid convective flow in a permeable cavity considering various shapes for nanoparticles. Int J Hydrog Energy 42:19611-19621

38. Sheikholeslami M (2018) Solidification of NEPCM under the effect of magnetic field in a porous thermal energy storage enclosure using CuO nanoparticles. J Mol Liq 263:303-315

39. Sheikholeslami $M$ (2018) Numerical modeling of nano enhanced PCM solidification in an enclosure with metallic fin. J Mol Liq 259:424-438

40. Sheikholeslami M (2018) Numerical simulation for solidification in a LHTESS by means of nano-enhanced PCM. J Taiwan Inst Chem Eng 86:25-41

41. Sheikholeslami $M$ (2018) Influence of magnetic field on $\mathrm{Al}_{2} \mathrm{O}_{3}-\mathrm{H}_{2} \mathrm{O}$ nanofluid forced convection heat transfer in a porous lid driven cavity with hot sphere obstacle by means of LBM. J Mol Liquids 263:472-488

42. Sheikholeslami M (2018) Finite element method for PCM solidification in existence of CuO nanoparticles. J Mol Liq 265:347-355

43. Sheikholeslami M, Rokni HB (2018) Magnetic nanofluid flow and convective heat transfer in a porous cavity considering Brownian motion effects. Phys Fluids 30(1):012003. https://doi. org/10.1063/1.5012517

44. Sheikholeslami M, Ghasemi A (2018) Solidification heat transfer of nanofluid in existence of thermal radiation by means of FEM. Int J Heat Mass Transf 123:418-431

45. Sheikholeslami Z, YousefiKebria D, Qaderi F (2018) Nanoparticle for degradation of BTEX in produced water; an experimental procedure. J Mol Liquids 246:476-482. https://doi.org/10.1016/j. molliq.2018.05.096

46. Sheikholeslami Z, YousefiKebria D, Qaderi F (2018) Investigation of photocatalytic degradation of BTEX in produced waterusing $\mathrm{Y}^{-} \mathrm{Fe}_{2} \mathrm{O}_{3}$ nanoparticle. J Therm Anal Calorim. https://doi. org/10.1007/s10973-018-7381-x

47. Sheikholeslami M, Mahian O (2019) Enhancement of PCM solidification using inorganic nanoparticles and an external magnetic field with application in energy storage systems. J Clean Prod 215:963-977

48. Sheikholeslami M (2019) New computational approach for exergy and entropy analysis of nanofluid under the impact of Lorentz force through a porous media. Comput Methods Appl Mech Eng 344:319-333

49. Sheikholeslami M (2019) Numerical approach for $\mathrm{MHD} \mathrm{Al}_{2} \mathrm{O}_{3}-$ water nano fluid transportation inside a permeable medium using innovative computer method. Comput Methods Appl Mech Eng 344:306-318

50. Sancho M, Arnal JM (2013) Treatment of hospital radioactive liquid wastes from RIA (radioimmunoassay) by membrane technology. DES 321:110-118. https://doi.org/10.1016/j.desal .2013.03.032

51. Taghizadeh M, Yousefi Kebria D, Qaderi F (2019) Benzene and toluene removal from saline water with coupled membrane process and nanophotocatalyst. J Pet Res 27(10300695):168-179

52. Taghizadeh M, Yousefi Kebria D, Qaderi F (2019) Effect of biosurfactant as a novel draw solution on photocatalytic treatment and desalination of produced water by different forward osmosis membranes. Water Sci Technol Water Supply. https:// doi.org/10.2166/ws.2019.154

53. Tamadoni A, Qaderi F (2019) Optimization of soil remediation by ozonation forPAHs contaminated soils. Sci Eng, Ozone. https ://doi.org/10.1080/01919512.2019.1615865

54. Tavakoli Moghadam M, Qaderi F (2019) Modeling of petroleum wastewater treatment by $\mathrm{Fe} / \mathrm{Zn}$ nanoparticles using the response surface methodology and enhancing the efficiency by scavenger. Res Phys 15:102566-102576. https://doi. org/10.1016/j.rinp.2019.102566

55. Tiwari B, Sellamuthu B, Ouarda Y, Drogui P, Tyagi RD, Buelna G (2016) Review on fate and mechanism of removal of pharmaceutical pollutants from wastewater using biological approach. Bioresour Technol 224:1-12

56. Walia S, Murleedharn C, Band J, Kanwar M, Kumar A (2016) Current medicine research and practice quantitation of antibiotic resistance genes pollution in hospital waste water effluent and Urban Clinton River Water, Michigan, USA. Indian J Rheumatol 6(4):149-151. https://doi.org/10.1016/j.cmrp.2016.07.005

57. Wijekoon KC, Hai Fl, Kang J, Price WE, Guo W, Ngo HH et al (2013) The fate of pharmaceuticals, steroid hormones, phytoestrogens, UV-filters and pesticides during MBR treatment. Bioresour Technol 144:247-254. https://doi.org/10.1016/j.biortech.2013.06.097

58. Yavari SM, Qaderi F (2018) Determination of thermal pollution of water resources caused by Neka power plant through processing satellite imagery. Environ Dev Sustain. https://doi. org/10.1007/s10668-018-0272-2

59. Yu S, Sun P, Zheng W, Chen L, Zheng X, Han J et al (2014) The effect of COD loading on the granule-based enhanced biological phosphorus removal system and the recoverability. Bioresour Technol 2014(171):80-87

60. Zahara P, Juan MDP, Jose AZ, Juan AC (2016) Application of intensified Fenton oxidation to the treatment of hospital wastewater: kinetics, ecotoxicity and disinfection. Biochem Pharmacol. https://doi.org/10.1016/j.jece.2016.09.019

61. Zhang X, Chen X, Zhang C, Wen H, Guo W, Ngo HH (2016) Effect of filling fraction on the performance of sponge-based moving bed biofilm reactor. Bioresour Technol 219:762-767. https://doi. org/10.1016/j.biortech.2016.08.031

Publisher's Note Springer Nature remains neutral with regard to jurisdictional claims in published maps and institutional affiliations. 